\title{
Young Egyptians' Uses and Gratifications of Mobile News
}

Dr. Abdelmohsen Hamed Okela

Department of Educational Media, Faculty of Specific Education, Minia University, Egypt

1. Introduction:

Portability, or mobility is a key feature that characteristics the vision of communication media today (Ishii, 2006), currently, users utilize a variety of mobile devices (such as mobile phones, Tablets, laptops), right now the widest spreading technology with an extensive use in Egypt, particularly among young people, is mobile phones, according to figures published in 2018 by The Group Special Mobile Association (GSMA) which provides analysis on global mobile operator data clearly referred that Egypt has 103.2 million mobile connections (Chiara Garbellini, 26 November 2018). 
Mobile devices have been a mainstay in our daily life, recently gathered statistics on Internet usage indicate that news consumption occurs mostly online, and that we are more likely to get news and information from mobile devices (Rowley, 2015). Mobile devices are largely commonplace in contemporary society, primarily mobile app software community is enormous and it is steadily increasing, in January 2017 the number of available applications for mobile phones reach more than 3 million apps available for the Android platform with more than 1.300 application every day, and 2.2 million for Apple's iPhone. In 2015 the number of iPhone apps downloads was 25 billion and 50 billion downloads of Android apps (Dogtiev, 2018).

Today mobile users can access to updated news in any place and at any time, they are browsing mobile websites, installing news applications, and messaging service alerts (O. J. D. j. Westlund, 2013). News is consuming increasingly on a plurality of devices, such as mobile devices, which have created multiple choices altered audience ways of news consumption, and have enabled users to follow and obtain the news (Van Damme, Courtois, Verbrugge, De Marez, \& Communication, 2015).

Mobile news' adoption has followed the rapid adoption of mobile devices. (89\%) of users are consuming news by mobile, particularly, young people prefer mobile phone as the greatest tool to get breaking news, the majority of respondents $(72 \%)$ confirmed that they access to news via mobile applications (Alsridi, 2018). The ability to access to news while on the go is a crucial factor for mobile news consumption (Schmitz Weiss, 2018). In the meantime, major news corporations (eg; Al Jazeera, BBC Arabic, etc.) have released their own mobile apps to push breaking news and more specific functions to users, and to directly interact with them.

In fact, news content is the widest spreading of mobile content; simplistic mobile interface with a unique set of features such as a small touchscreen, data storage, and ubiquitous information access greatly facilitates news access, users can easily select mobile news channels by browsing mobile news websites and social networking services such as Twitter and Facebook, which comprise a large component of online news services for users to share, bookmark news content (Shim, You, Lee, \& Go, 2015).

\section{Literature review}

\subsection{Mobile news.}

By 2025 The number of mobile users will reach 5.9 billion, equal to $71 \%$ of the total population of the world. With 5 billion of mobile internet users (Sivakumaran \& Iacopino, 2018). The Internet is the first source to get the latest news $(67 \%)$, and young people prefer mobile phone as the greatest tool to get breaking news, the majority of respondents $(72 \%)$ confirmed that they access to news via mobile applications (Alsridi, 2018).

Pew research conducted in 2012, which reported that News is a prominent part of people's activities on their mobile devices, $62 \%$ of mobile phone and $64 \%$ of tablet users use them for news at least weekly and $52 \%$ and $56 \%$ respectively obtain news daily, furthermore, $28 \%$ of smartphone owners mostly access news through apps (Mitchell, Rosenstiel, Santhanam, \& Christian, 2012). 
At the meantime, news consumption become digital, via mobile phones and other hand held devices, using mobile devices authorized users to consume news on the go in various forms (Lehuidoux, 2018; Van Damme et al., 2015). The ubiquity of mobile devices, enabling users to access the news anytime and anywhere, at home and at workplace, statistics reveal that users are accessing the news by their mobile devices when they wake up, and before going bed (O. Westlund, Färdigh, \& Communication, 2015). According to Reuters Institute Digital news report, more than half of mobile users (53\%) utilize their mobile devices to news access (Newman \& Levy, 2016). Users utilize communication apps every hour of the day, especially in the afternoon and evening. News apps is used in the morning. And Social and news apps an equal usage (Böhmer, Hecht, Schöning, Krüger, \& Bauer, 2011).

The extensive smartphones usage is to keep up with the news, $47.8 \%$ of mobile users are checking headlines, and 20.6\% read detailed articles daily. $44 \%$ of tablet and mobile owners reported that these devices are their main source for checking or reading news (Incollingo, 2018).

Most mobile users are using mobile news during the day (49\%), and (84\%) use mobile news, audience rated the Internet as news source they used frequently, pursued by mobile phone, then Television (Chan-Olmsted, Rim, Zerba, \& Quarterly, 2013).

A positive relationship between use mobile phones to get news and other devices (such as: Computer, Television and Print). News sessions on cell phones tend to be shorter than on other platforms, users spend less than 12 minutes on smartphones, compared with 30 minutes on television. Furthermore, mobile devices news users obtain news from multiple platforms. (Molyneux, 2018). Desktop visitors to news sites spend more time per visit than do mobile visitors, although, the enormous amount of internet traffic to news websites coming from mobile devices (Lu \& Holcomb, 2016; Mitchell \& Holcomb, 2015).

Users can easily install and use mobile applications on their own needs and interests, with the diverse mobile news services users select their online news channels based on their preferences, mobile apps provide news content from users' preferred news sources (Verkasalo, López-Nicolás, Molina-Castillo, Bouwman, \& Informatics, 2010).

One of these mobile apps is social media platforms through mobile devices, which people enjoy sharing news content, these sharing services are deeply integrated into most major news websites (Messing \& Westwood, 2014)

According to the Arab Young Survey (2018), (63\%) of young Arabs get their news from social media and $(51 \%)$ via television. The wide growth of social media as a news source is driven by Facebook, with (49\%) of young Arabs get news on Facebook daily (ASDA'A, 2018).

A study by Strategy \& Group (“Understanding the Arab Digital Generation”, 2018) on digital lifestyles of young Arabs indicated that (61\%) spend daily more than two hours on social networking platforms, and there are $(78 \%)$ prefer the Internet to watching television (Sabbagh et al., 2018), (51\%) use social media as a source of news by the week, and (12\%) say that social media is the main source of news. And the most important network is Facebook that empowers users to follow, find, read, 
watch, and share the news (Newman \& Levy, 2016).

Social media has empowered users with similar interests to talk about news and share that with others, today Facebook is a prime source for news, nearly half (48\%) of internet users obtain news from Facebook (Mitchell, Gottfried, Kiley, \& Matsa, 2014). Furthermore, social media equal news organizations websites and apps as a source of news, $(26 \%)$ of online news consumers get news through social media, and $(23 \%)$ from news organizations' websites and apps (Mitchell, Gottfried, Shearer, \& $\mathrm{Lu}, 2017)$.

Facebook is the most popular social networks in news consumption, as a consequence of users spend almost as much time on Facebook; thereby, consuming more news stories while browsing their news feeds (Litsa, 2017). Today, users are relying on Facebook more and more as a news source (Anspach, Jennings, \& Arceneaux, 2019). Because Facebook is the most widely adopted social media network, and more users follow news brands and journalists on Facebook than they do on other social media (Keib \& Wojdynski, 2019).

\subsection{Uses and gratifications of mobile news.}

The theory of uses and gratifications clarifies psychological and social origins of needs that lead media exposure and selection to gratify individuals' needs. This theory assumes that individuals are active and goal-oriented, their motivations drive media exposure, and they select media to fulfill their gratifications ( $\mathrm{Ng} \&$ Zhao, 2018).

Today, people have an extensive variety of digital technologies which provide them with new channels to obtain information, engagement, satisfy personal needs and offer additional features of uses and gratifications: such as; interactivity, demassification, and asynchroneity (Bodine, 2018). A six-dimensional definition of interactivity embraces (a complex of available choices, users' effort they must apply, responsive to users, tracking of information use, the simplicity to add information, and interpersonal communication acceleration) (Kiousis \& society, 2002). Demassification refers to user's ability to select from a wide spread menu and individual's control over the medium (Ruggiero \& society, 2000). Asynchroneity refers to that media messages may be overlapped in time. In regard to audio usage, user can manipulate media; for example, save music on an MP3 player, to listen it later (Albarran et al., 2007).

Uses and gratifications theory interest in a key question; for what reason do individuals utilize media? Seen the media as serving different needs of audience, for instance, for cohesion, cultural flow, social control and a huge flowing of various information. This presume that individuals use media on purpose, such as management of personality, amusement, adaptation and establishment of identity (McQuail, 2010).

The main assumptions of uses and gratifications theory are:

(1) Media and content selection is a reasonable and directed process to fulfil specific needs and satisfactions.

(2) Audience is active and aware of needs that associated to media. Media content features (such as culture, aesthetic and attraction) have a tinny role in attracting individuals than satisfaction of different personal and social goals, for instance 
(amusement, relaxation, experience participation, time lapse, etc.).(McQuail, 2010).

\section{Problem statement}

With all of aforementioned, the availability of mobile news sources and its wide spreading, and how people use these sources to get news is influenced by fulfill some gratifications. Uses and gratifications theory hypothesizes that people consciously select media in order to gratify their needs, and that gratifications obtain is the basic goal of media use (Rokito, Choi, Taylor, \& Bazarova, 2019). therefore, this study helps to elucidate young Egyptians' uses and gratifications of mobile news, and determines pattern of use and the most extensive news app (eg; social networking services, and news organization apps) they frequently use.

\section{Method}

The study uses an analytical descriptive method to measure and describe young Egyptians mobile news gratifications, a quantitative research method attempts to collect quantifiable information to be used for statistical analysis of the young Egyptians' mobile and other media for news consumption.

\subsection{Participants.}

The study used a random sample from Minya university students. data was collected using a self-reported survey. A total of 326 student participated, after eliminating incomplete questionnaires, 300 responses were analyzed 281 subjects consume mobile news via smartphones (93.7\%) and 19 do not follow news via mobile device $(6.3 \%)$. Among the participants, $(51.2 \%)$ were male and $(48.8 \%)$ were female. The average age of respondents was 19.5 years old. On average, the participants spent 90 minutes (ranging from 60 minutes up to 180 minutes) per day browsing the mobile Internet, and spent $26 \mathrm{~min}$ (ranging from $5 \mathrm{~min}$ up to $90 \mathrm{~min}$ ) accessing news on their smartphones. In addition, 71\% from participants who follow mobile news get their news from social media apps via their smartphones.

\subsection{Research hypothesis}

H1. High intensive Internet users will be more likely to have higher levels of mobile news usage than low intensive Internet users.

H2. High intensive mobile device users will be more likely to have higher levels of mobile news usage than low intensive mobile device users.

H3. Mobile news consumption has a positive relation with gratifications dimensions.

\subsection{Research questions}

Based on the research objects, this research presents the following research questions:

RQ1. Do mobile devices attract young Egyptians as a source of news?

RQ2. Why do young Egyptian use mobile device for acquiring news?

RQ3. On which platforms do young Egyptians get news?

RQ4. Is mobile device displacing or supplementing other news media for young Egyptians?

RQ5. Which mobile news apps (News apps, Social networks apps, TV news channels apps and newspapers apps) are the most popular news sources among young Egyptians? 
RQ6. What are the gratifications that are most sought among young Egyptians in using mobile news?

\subsection{Measures}

The questionnaire is composed of two parts, first part measure mobile news and other news sources, and the second part measure mobile news gratifications.

\subsubsection{Mobile news and other news source use.}

This part consists of 12 questions interest to measure (Mobile news interest, news sources, internet use, internet use duration, internet use for news consumption, internet use for news duration, news apps, mobile device as a source of news, and reasons to obtain news from mobile devices).

\subsubsection{Mobile news gratifications.}

Mobile news gratifications scale is a five-point Likert type scale including 27 items under four dimensions (Interactivity, Surveillance, Social utility, and Escape). The answers to these items are as follows: (1) Strongly Disagree, (2) Disagree, (3) Neutral, (4) Agree, (5) Strongly Agree. Some items out of these 27 were taken from the research of (Masouras, Siakalli, \& Papademetriou, 2015), (Leung, Wei, \& Quarterly, 2000), and (O. Westlund, 2015).

Mobile news gratifications scale was tested for reliability. A high reliability coefficient indicates a highly reliable instrument. The reliability coefficient based on the Cronbach Alpha method for the scale as a whole is 0.927 .

The reliability estimates for each dimension of gratifications scale are shown in (Table 1):

Table 1. Cronbach Alpha reliability coefficients

\begin{tabular}{lll}
\hline Dimension & N of Items & Reliability \\
Interactivity & 9 & 0,782 \\
Surveillance & 9 & 0.883 \\
Social utility & 4 & 0.827 \\
Escape & 5 & 0.899 \\
\hline
\end{tabular}

Young Egyptians' scores derived from the five-point Likert type scale are not standard due to the differences in item numbers of dimensions. Thus, the raw scores were changed into standard scores that are minimum 27 and maximum 135. The levels corresponding to the scores derived from the mobile news gratifications scale were determined as follows (Table 2): 
Table 2. distribution of mobile news gratifications scale scores

\begin{tabular}{llll}
\hline Scale score & Status & .Freq & $\%$ \\
$48.6-27$ & Very Low Mobile News Gratifications & 0 & 0 \\
$75.6-49$ & Low Mobile News Gratifications & 3 & 1.1 \\
$102.6-76$ & Medium Mobile News Gratifications & 83 & 29.5 \\
$129.6-103$ & High Mobile News Gratifications & 170 & 60.5 \\
$135-130$ & Very High Mobile News Gratifications & 25 & 8.9 \\
\hline $\mathrm{N}=281$ & & &
\end{tabular}

\section{Findings}

\subsection{Mobile news consumption}

The study found that the most frequently news source was mobile phone $(38.4 \%)$ of respondents always use their mobile devices to obtain news, $(41.3 \%)$ sometimes get news through their mobile phones, and (20.3\%) don not prefer to follow news via mobile device for some reasons (Table 3).

Table 3. Users do not prefer mobile device as a source of news for these reasons.

Reasons

In general, I do not care to follow news

.Getting news via other sources (eg: TV, Newspapers) is enough

.Reading news via a tinny screen is exhausting for me

.I don't have time to read news when I use mobile

I prefer to spend time with my favorite game rather than reading news

$\mathrm{N}=19$

Results indicate that young Egyptians said that mobile device is a convenient medium to get news $(54.9 \%)$. to clarify the reasons behind the dominance of mobile devices for news consumption, university students were asked about reasons for preferring mobile as a source of news (Table 3) are easiness to get news anywhere anytime $(54.4 \%)$, and simplicity to pursue news $(51.2 \%)$. 
Table 4. Use mobile phone for news reasons

Reasons

.Freq

$\%$

Easiness to get news anywhere anytime

Simplicity to pursue news

I can customize news according to my interests

I can follow news while practice other activities

Various mobile apps for news

I can easily share and comment on news

In regard to news sources, Mobile devices have become one of the most common ways young Egyptians obtain news from, outpacing desktop or laptop computers and traditional media like TV and print. Roughly nine-in-ten Egyptian university students $(93 \%)$ get news on a mobile phone, $9 \%$ from Tablets, $18 \%$ get news on a desktop and $15 \%$ on a laptop, and $43 \%$ get news from TV and $6 \%$ from print. Mobile news consumption source at the last week, the results indicate that $83.9 \%$ of young Egyptians use mobile devices, and $29 \%$ use TV, and $5.4 \%$ use print and tablet, 10.8 $\%$ use laptop to get news, $11.8 \%$ obtain news from desktop (Graph 1).

\section{Graph 1. News sources use and news sources last week}

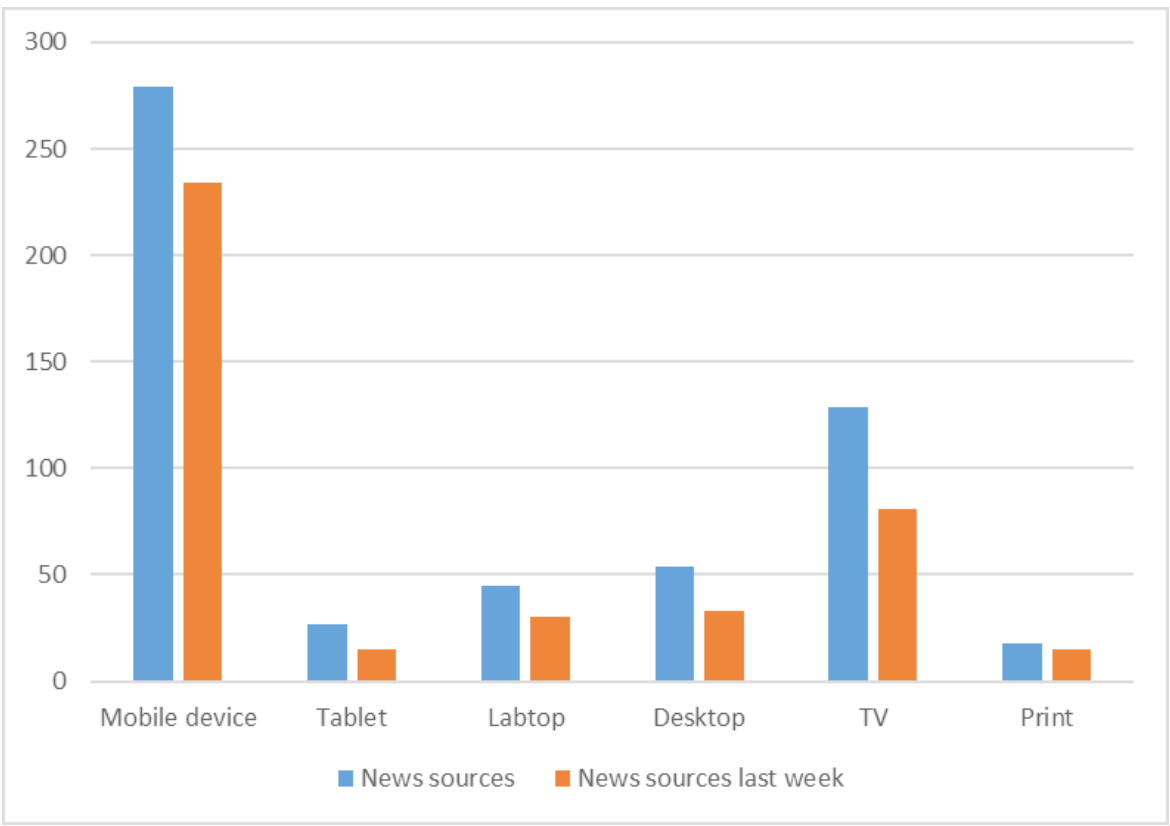


Findings illustrate that smartphone owners rely on social networks a bit more for news. Nearly half of smartphone news users, $47 \%$, receive news through social networks apps, 24\% from newspapers apps, 12\% get news from TV news channels apps, 10\% utilizes search engines for browsing news, and only $7 \%$ from young Egyptians use news apps (eg: Nabd and Rasd). (Graph 2).

\section{Graph 2. Mobile news apps consumption}

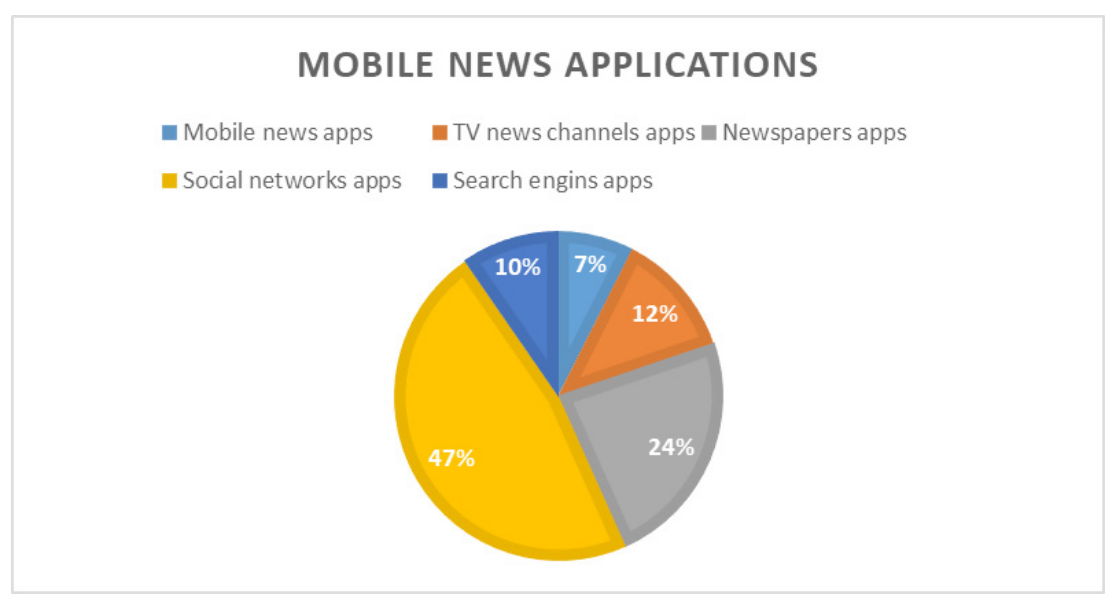

\subsection{Mobile news gratifications}

More than half the sample (51.2\%) answered (Strongly agree) to interactivity dimension of mobile news gratifications as "I can skip adds and go directly to what I need to watch or read). And 55.9\% answered (agree) to social utility dimension as "To have something to talk about with others". All average scores of distribution for mobile news gratifications are given in (Table 4). As it seen, high average 4.39 was the answer of "I can share and disseminate news with friends" in interactivity dimension. The total average scores of mobile news gratifications dimensions were: interactivity (4.26), Surveillance (4.07), Social utility (3.89) and Escape (3.66) (Table 5). 
Table 5. Distribution of answers given to mobile news gratifications scale.

\begin{tabular}{|c|c|c|c|c|c|c|c|c|c|c|c|c|}
\hline \multirow{2}{*}{\multicolumn{2}{|c|}{ Items }} & \multicolumn{2}{|c|}{ Very Disagree } & \multicolumn{2}{|c|}{ Disagree } & \multicolumn{2}{|c|}{ Neutral } & \multicolumn{2}{|c|}{ Agree } & \multicolumn{2}{|c|}{$\begin{array}{l}\text { Strongly } \\
\text { Agree }\end{array}$} & \multirow[t]{2}{*}{ Average } \\
\hline & & .Freq & $\%$ & .Freq & $\%$ & .Freq & $\%$ & .Freq & $\%$ & .Freq & $\%$ & \\
\hline \multirow[t]{9}{*}{ Interactivity } & 1 & 0 & 0 & 0 & 0 & 27 & 9.6 & 125 & 44.5 & 129 & 45.9 & 4.36 \\
\hline & 2 & 0 & 0 & 0 & 0 & 60 & 21.4 & 137 & 48.8 & 84 & 29.9 & 4.09 \\
\hline & 3 & 6 & 2.1 & 3 & 1.1 & 47 & 16.7 & 134 & 47.7 & 91 & 32.4 & 4.07 \\
\hline & 4 & 0 & 0 & 3 & 1.1 & 38 & 13.5 & 96 & 34.2 & 144 & 51.2 & 4.36 \\
\hline & 5 & 0 & 0 & 6 & 2.1 & 28 & 10 & 98 & 34.9 & 149 & 53 & 4.39 \\
\hline & 6 & 0 & 0 & 3 & 1.1 & 34 & 12.1 & 98 & 34.9 & 146 & 52 & 4.38 \\
\hline & 7 & 3 & 1.1 & 0 & 0 & 37 & 13.2 & 113 & 40.2 & 128 & 45.6 & 4.29 \\
\hline & 8 & 0 & 0 & 0 & 0 & 61 & 21.7 & 110 & 39.1 & 110 & 39.1 & 4.17 \\
\hline & 9 & 0 & 0 & 6 & 2.1 & 44 & 15.7 & 107 & 38.1 & 124 & 44.1 & 4.24 \\
\hline \multirow[t]{9}{*}{ Surveillance } & 10 & 0 & 0 & 6 & 2.1 & 63 & 22.4 & 104 & 37 & 108 & 38.4 & 4.12 \\
\hline & 11 & 3 & 1.1 & 0 & 0 & 44 & 15.7 & 120 & 42.7 & 114 & 40.6 & 4.22 \\
\hline & 12 & 3 & 1.1 & 4 & 1.4 & 45 & 16 & 131 & 46.6 & 98 & 34.9 & 4.13 \\
\hline & 13 & 0 & 0 & 3 & 1.1 & 40 & 14.2 & 142 & 50.5 & 96 & 34.2 & 4.18 \\
\hline & 14 & 13 & 4.6 & 21 & 7.5 & 108 & 38.4 & 85 & 30.2 & 54 & 19.2 & 3.52 \\
\hline & 15 & 0 & 0 & 12 & 4.3 & 69 & 24.6 & 133 & 47.3 & 67 & 23.8 & 3.91 \\
\hline & 16 & 3 & 1.1 & 9 & 3.2 & 46 & 16.4 & 115 & 40.9 & 108 & 38.4 & 4.12 \\
\hline & 17 & 0 & 0 & 0 & 0 & 51 & 18.1 & 134 & 47.7 & 96 & 34.2 & 4.16 \\
\hline & 18 & 3 & 1.1 & 0 & 0 & 31 & 11 & 125 & 44.5 & 122 & 43.4 & 4.29 \\
\hline \multirow{4}{*}{$\begin{array}{l}\text { Social } \\
\text { Utility }\end{array}$} & 19 & 3 & 1.1 & 13 & 4.6 & 43 & 15.3 & 157 & 55.9 & 65 & 23.1 & 3.95 \\
\hline & 20 & 3 & 1.1 & 7 & 2.5 & 55 & 19.6 & 142 & 50.5 & 74 & 26.3 & 3.99 \\
\hline & 21 & 6 & 2.1 & 16 & 5.7 & 96 & 34.2 & 102 & 36.3 & 61 & 21.7 & 3.70 \\
\hline & 22 & 3 & 1.1 & 19 & 6.8 & 71 & 25.3 & 91 & 32.4 & 97 & 34.5 & 3.93 \\
\hline \multirow[t]{5}{*}{ Escape } & 23 & 6 & 2.1 & 3 & 1.1 & 77 & 27.4 & 106 & 37.7 & 89 & 31.7 & 3.96 \\
\hline & 24 & 9 & 3.2 & 26 & 9.3 & 95 & 33.8 & 86 & 30.6 & 65 & 23.1 & 3.61 \\
\hline & 25 & 9 & 3.2 & 21 & 7.5 & 67 & 23.8 & 99 & 35.2 & 85 & 30.3 & 3.82 \\
\hline & 26 & 19 & 6.8 & 36 & 12.8 & 97 & 34.5 & 51 & 18.1 & 78 & 27.8 & 3.47 \\
\hline & 27 & 24 & 8.5 & 30 & 10.7 & 93 & 33.1 & 64 & 22.8 & 70 & 24.9 & 3.45 \\
\hline
\end{tabular}

There was a positive correlation between internet use, internet use for news, and mobile use and young Egyptians of mobile news consumption $(\mathrm{p}<0.01)$. spearman correlation value was determined as $0.136,0.469$ and 0.388 respectively (Table 6). 
Table 6. Correlations among mobile news consumption and internet and mobile use.

\begin{tabular}{|ll|}
\hline & Mobile news consumption \\
\hline Internet use & ${ }^{* *} 0.136$ \\
\hline Internet use for news & ${ }^{* *} 0.469$ \\
\hline Mobile use & ${ }^{* *} 0.388$ \\
\hline$* * \mathrm{p}<0.01$ &
\end{tabular}

There was a positive correlation between mobile news consumption and young Egyptians of mobile news gratifications (Interactivity, Surveillance, Social utility, and Escape) $(\mathrm{p}<0.01)$. spearman correlation value was determined as $0.250,0.227,0.205$ and 0.156 respectively (Table 7 ).

Table 7. Correlations among mobile news use and young Egyptians' gratifications.

\begin{tabular}{|lllll|}
\hline & Interactivity & Surveillance & Social utility & Escape \\
\hline Mobile news consumption & ${ }^{* *} 0.250$ & ${ }^{*} 0.227$ & ${ }^{* *} 0.205$ & ${ }^{* *} 0.156$ \\
\hline$* * \mathrm{p}<0.01$ & & &
\end{tabular}

\section{Discussion and conclusion}

This study was conducted to determine young Egyptians' mobile news gratifications and to research the relationship between mobile and other media use and mobile news

c. consumption. $23 \%$ of young people use mobile devices, and $22 \%$ social networks apps for news. According to (Incollingo, 2018) that one of the most popular activities on mobile devices is news consumption. According to this result, young Egyptians in our sample group can be said to have the same activity on their mobile devices. Today, mobile news consumption with mobile devices and tablets have a widespread accepted (Chan-Olmsted, Rim, Zerba, \& Quarterly, 2013; Struckmann, Karnowski, \& Informatics, 2016; Westlund, 2015).

Due to the fact that audience members are mainly responsible for media selecting to gratify their needs according to uses and gratifications theory (Littlejohn \& Foss, 2010). Studies used similar components to measure users' gratifications, the uses and gratifications components consists of four dimensions, which are: information, discussion, entertainment, and surveillance (Masouras, Siakalli, \& Papademetriou, 2015; Van Cauwenberge, d'Haenens, \& Beentjes, 2010; Vincent, Basil, \& Media, 1997). Along with this paper has introduced interactivity as a new dimension of mobile news gratifications, this dimension includes (Entertainment, and information seeking). Based on what have mentioned, the dimensions of uses and gratifications theory applied in this study include: 1) Interactivity; 2) Surveillance; 3) Social utility; 4) Escape.

The average of interactivity dimension was found at high level (4.26). a positive 
relationship was found between Mobile news consumption and gratifications scale with a high correlation for interactivity dimension (0.250). average mobile news gratifications were found at high level (from 3.58 to 4.39). young Egyptians have high scores at mobile news gratifications scale (60.5\%) have high score (more than 103 from 135$)$, and (8.9\%) have very high score (more than 130 from 135).

The results of the study revealed that the percentage of interest in news by young Egyptians is high, nearly more than three quarters $(82.6 \%)$ of the sample are quite interested in news, and (17.4\%) very interested in follow news, On the question of "How young Egyptians get news?", respondents stated that mobile phones are more convenient to obtain news, approximately nine in ten young Egyptians get news from mobile phones (93\%). Another important finding was that social networks apps (eg: Facebook, Twitter) are the first source that young Egyptians access news from mobile devices $(47 \%)$.

In general, the study has found that young Egyptians are increasingly associated with the use of mobile news, particularly smartphone applications are an emerging tool for young adults in Egypt to follow news.

Future research may expand on the list of relevant attributes to include different types of mobile news apps. For instance, social networks and news apps (eg: Nabd, Rasd) are more relevant to the mobility and immediacy nature of mobile news, and it will also be interesting to young news consumers to see how they vary in their use of mobile news. Utilizing Diffusion of Innovation Theory, one might also explore the benefits behind mobile news adoption. Finally, news consumption via social networks apps through either mobile devices or computers, and news credibility is another relevant area of investigation for this particular group of users. 


\section{References}

Alsridi, H. (2018). Uses and Gratifications of Online News among Young Adults in Bahrain. Athens Journal Of Mass Media And Communications, 4, 63-80. doi:10.30958/ ajmmc.4.1.4

ASDA'A, B. M. J. R. M. (2018). Arab Youth Survey 2018: A decade of hopes \& fears. 12, 2018.

Böhmer, M., Hecht, B., Schöning, J., Krüger, A., \& Bauer, G. (2011). Falling asleep with Angry Birds, Facebook and Kindle: a large scale study on mobile application usage. Paper presented at the Proceedings of the 13th international conference on Human computer interaction with mobile devices and services.

Chan-Olmsted, S., Rim, H., Zerba, A. J. J., \& Quarterly, M. C. (2013). Mobile news adoption among young adults: Examining the roles of perceptions, news consumption, and media usage. 90(1), 126-147.

Chiara Garbellini, J. S. G. A. (26 November 2018 ). The Mobile Economy Middle

East \& North Africa 2018. 35.

Dogtiev, A. (2018). App Download and Usage Statistics 2017. Business of Apps. In.

Incollingo, J. S. J. N. R. J. (2018). "I'ma news junkie... I like being informed": Mobile news use by a newspaper's digital subscribers. 0739532918775672.

Lehuidoux, M. (2018). Social Media and News Consumption Among Canadian Millennials.

Leung, L., Wei, R. J. J., \& Quarterly, M. C. (2000). More than just talk on the move: Uses and gratifications of the cellular phone. 77(2), 308-320.

Litsa, T. (2017). How news consumption changed with social media. In: ClikZ.

Lu, K., \& Holcomb, J. J. S. o. t. n. m. (2016). Digital news audience: Fact sheet.

Masouras, A., Siakalli, M., \& Papademetriou, C. (2015). Understanding Online News: Uses and Gratifications of Mainstream News Sites and Social Media.

MCIT. (2018). ICT Indicators in Brief. Retrieved from http://www.mcit.gov.eg/ Upcont/Documents/Publications_25112018000_ar_AR_ICT_Indicators_in_brif September 2018.pdf

Mitchell, A., Gottfried, J., Kiley, J., \& Matsa, K. E. J. P. R. C. (2014). Political polarization \& media habits. 21.

Mitchell, A., Gottfried, J., Shearer, E., \& Lu, K. J. P. R. C. (2017). How Americans encounter, recall and act upon digital news.

Mitchell, A., \& Holcomb, J. J. P. R. C. (2015). State of the news media 2015. 29.

Mitchell, A., Rosenstiel, T., Santhanam, L. H., \& Christian, L. J. P. R. J. P. (2012). The future of mobile news. The explosion in mobile audiences and a close look at what it means for news.

Molyneux, L. J. D. J. (2018). Mobile news consumption: A habit of snacking. 6(5), 634-650.

Newman, N., \& Levy, D. A. L. (2016). Digital News Report. Reuters Institute for the Study of Journalism, Oxford.

Rowley, C. (2015). Choice, Ethics, Self-Images: A Study of Mobile News Consumption Among Canadian University Students.

Sabbagh, K., Mourad, M., Kabbara, W., Shehadi, R., Samman, H., Insight, I. C. J. 
B., \& Company. (2018). Understanding the Arab Digital Generation.

Schmitz Weiss, A. J. N. R. J. (2018). Location-based news in mobile news apps: Broadcast leads in geolocated news content, newspapers lag behind. 39(1), 42-54. Sivakumaran, M., \& Iacopino, P. J. G. I. (2018). The Mobile Economy 2018.

Van Damme, K., Courtois, C., Verbrugge, K., De Marez, L. J. M. M., \& Communication. (2015). What's APPening to news? A mixed-method audiencecentred study on mobile news consumption. 3(2), 196-213.

Verkasalo, H., López-Nicolás, C., Molina-Castillo, F. J., Bouwman, H. J. T., \& Informatics. (2010). Analysis of users and non-users of smartphone applications. 27(3), 242-255.

Westlund, O. (2015). News consumption in an age of mobile media: Patterns, people, place, and participation. In: SAGE Publications Sage UK: London, England.

Westlund, O., Färdigh, M. A. J. M. M., \& Communication. (2015). Accessing the news in an age of mobile media: Tracing displacing and complementary effects of mobile news on newspapers and online news. 3(1), 53-74.

Westlund, O. J. D. j. (2013). Mobile news: A review and model of journalism in an age of mobile media. 1(1), 6-26.

Albarran, A. B., Anderson, T., Bejar, L. G., Bussart, A. L., Daggett, E., Gibson, S., . . Horst, J. L. J. J. o. R. S. (2007). “What happened to our audience?” Radio and new technology uses and gratifications among young adult users. 14(2), 92-101.

Anspach, N. M., Jennings, J. T., \& Arceneaux, K. (2019). A little bit of knowledge: Facebook's News Feed and self-perceptions of knowledge. 6(1), 2053168018816189. doi:10.1177/2053168018816189

Bodine, K. M. (2018). College Students' Use of Digital and Traditional Media: Uses and Gratifications Approach.

Chan-Olmsted, S., Rim, H., Zerba, A. J. J., \& Quarterly, M. C. (2013). Mobile news adoption among young adults: Examining the roles of perceptions, news consumption, and media usage. 90(1), 126-147.

Incollingo, J. S. J. N. R. J. (2018). "I'ma news junkie... I like being informed": Mobile news use by a newspaper's digital subscribers. 0739532918775672.

Ishii, K. J. J. o. c. (2006). Implications of mobility: The uses of personal communication media in everyday life. 56(2), 346-365.

Keib, K., \& Wojdynski, B. (2019). Staying Alive: TV News Facebook Posts, Perceived Credibility, andEngagementIntent.13(1),3-22.doi:10.1177/1931243118767733

Kiousis, S. J. N. m., \& society. (2002). Interactivity: a concept explication. 4(3), 355-383.

Littlejohn, S. W., \& Foss, K. A. (2010). Theories of human communication: Waveland press.

Masouras, A., Siakalli, M., \& Papademetriou, C. (2015). Understanding Online News: Uses and Gratifications of Mainstream News Sites and Social Media.

McQuail, D. (2010). McQuail's mass communication theory: Sage publications.

Messing, S., \& Westwood, S. J. J. C. R. (2014). Selective exposure in the age of social media: Endorsements trump partisan source affiliation when selecting news online. 41(8), 1042-1063. 
Ng, Y.-L., \& Zhao, X. (2018). The Human Alarm System for Sensational News, Online News Headlines, and Associated Generic Digital Footprints: A Uses and Gratifications Approach. Communication Research, O(0), 0093650218793739. doi:10.1177/0093650218793739

Rokito, S., Choi, Y. H., Taylor, S. H., \& Bazarova, N. N. (2019). Over-gratified, under-gratified, or just right? Applying the gratification discrepancy approach to investigate recurrent Facebook use. Computers in Human Behavior, 93, 76-83. doi:https://doi.org/10.1016/j.chb.2018.11.041

Ruggiero, T. E. J. M. c., \& society. (2000). Uses and gratifications theory in the $21 \mathrm{st}$ century. 3(1), 3-37.

Shim, H., You, K. H., Lee, J. K., \& Go, E. (2015). Why do people access news with mobile devices? Exploring the role of suitability perception and motives on mobile news use. Telematics and Informatics, 32(1), 108-117. doi:https://doi.org/10.1016/j. tele.2014.05.002

Struckmann, S., Karnowski, V. J. T., \& Informatics. (2016). News consumption in a changing media ecology: An MESM-study on mobile news. 33(2), 309-319.

Van Cauwenberge, A., d'Haenens, L., \& Beentjes, H. J. O. (2010). Emerging consumption patterns among young people of traditional and Internet news platforms in the Low Countries. 4(3).

Vincent, R. C., Basil, M. D. J. J. o. B., \& Media, E. (1997). College students' news gratifications, media use, and current events knowledge. 41(3), 380-392.

Westlund, O. (2015). News consumption in an age of mobile media: Patterns, people, place, and participation. In: SAGE Publications Sage UK: London, England. 


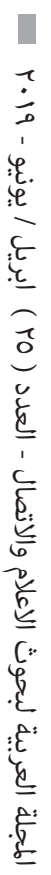

